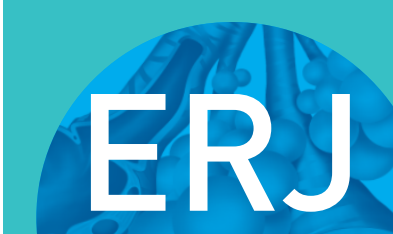

open research
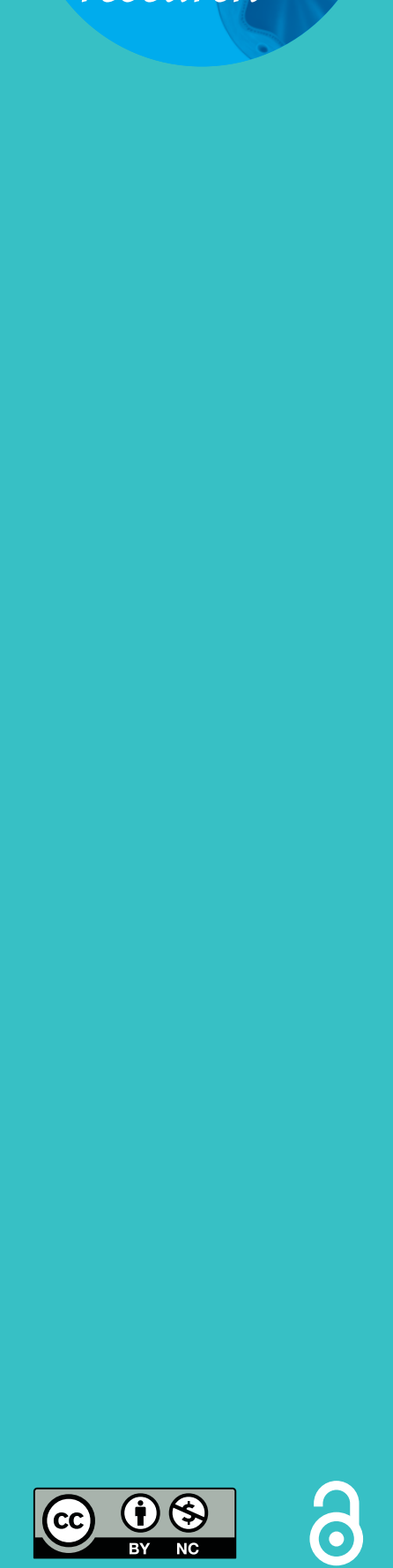

\title{
Tuberculosis elimination in Oman: winning the war on the disease
}

\section{Salah T. Al Awaidy}

Affiliation: Office of Health Affairs, Ministry of Health, Muscat, Oman.

Correspondence: Salah T. Al Awaidy, PO Box 393 PC 100, Muscat, Oman. E-mail salah.awaidydagmail.com

ABSTRACT In 2014, the World Health Assembly adopted the new End TB Strategy that targets ending tuberculosis (TB) by 2035. This article describes the progress made to eliminate TB in Oman.

Data from officials and other sources provided the information to assess the situation in Oman.

In the period 1981-1992, TB notifications decreased by 11\% per year. Between 1992 and 2016, the rates declined more slowly at $4.6 \%$ per year, i.e. from 16 to 7.8 per 100000 . During 2010-2016, 2352 TB cases (80\% males and 60\% Omani nationals) were reported. Bacteriologically confirmed TB cases decreased from 47 to 38 per million population, with a cumulative decline of $19 \%$. The success rate of TB treatment was $>87 \%$. Among the new cases, $1.2 \%$ were multidrug-resistant TB cases. TB mortality rate dropped by $39 \%$ between 1990 and 2016.

TB control efforts in Oman have produced remarkable effects. However, the pre-elimination threshold set at $<10$ notified TB cases per million population per year is not yet in reach. There is a need for an urgent national response and careful consideration of new available interventions.

@ERSpublications

The national TB control programme of Oman has enforced concrete steps to implement key TB elimination measures. The overall TB notification rate for all new $T B$ cases declined significantly from 91 to 7.8 per 100000 population during $1981-2016(\mathrm{p}<0.001)$. http://ow.ly/sZyJ30mrueV

Cite this article as: Al Awaidy ST. Tuberculosis elimination in Oman: winning the war on the disease. ERJ Open Res 2018; 4: 00121-2018 [https://doi.org/10.1183/23120541.00121-2018].

Received: July 282018 | Accepted after revision: Oct 122018

Copyright $\odot$ ERS 2018. This article is open access and distributed under the terms of the Creative Commons Attribution Non-Commercial Licence 4.0. 


\section{Introduction}

Tuberculosis (TB) is a major public health concern worldwide [1]. In 2016, TB affected 10.4 million people and killed 1.7 million worldwide with over 95\% from low- and middle-income countries [2].

"Ending TB" is a target that has been addressed by both the United Nations Sustainable Development Goals (SDG) 2016-2030 and the World Health Assembly resolution of 2014. In low TB burden countries, achieving incidence levels aligned with the established international targets requires additional tailored actions. The goals of the World Health Organization (WHO) End TB Strategy are to reduce the number of TB deaths by $95 \%$ and its incidence by $90 \%$ by 2035 , and to ensure that no family or patient incur catastrophic expenditures because of this disease [3-9].

With the vision of adapting the new End TB Strategy for low-burden countries and the progress made, in 2014, the WHO, along with the European Respiratory Society and other partners, established a framework for TB elimination in these countries. The framework states eight priority strategic interventions, which target reducing TB incidence, along with pre-elimination and elimination measures [3].

There are few publications on TB in Oman [10-13] describing the TB elimination initiative [14, 15]. This article summarises the progress made towards TB elimination in Oman, identifies the challenges to be confronted by the national TB control programme (NTP), highlights the lessons learnt and proposes the steps to reach the international targets towards TB elimination.

\section{Material and methods}

A retrospective study was undertaken on a 36-year assessment of the detection, management and treatment outcomes of TB cases (all forms) reported between 1981 and 2016 in Oman. Data were gathered from the national electronic case-based TB Registry, the annual health reports [16], the annual progress reports of the Ministry of Health $(\mathrm{MOH})$ and WHO global TB reports [1]. The information was analysed with a focus on the principal characteristics of reported TB cases (time, place, sex, age, residency and nationality), patient management (history of previous anti-TB treatment, localisation of disease, laboratory results, HIV status and treatment outcomes) and mortality rate.

The National Centre for Statistical and Information Census [17] was used to calculate rates per 100000 population. The projections of TB incidence in Oman were taken into account from 2011 to 2016. A p-value $<0.05$ was selected as a cut-off level for statistical significance with application of the Chi-squared test.

\section{NTP of Oman}

Approximately 4.4 million people live in the national territory of Oman; 78\% of them are living in urban areas, $22 \%$ in rural areas and $33 \%$ in the capital city of Muscat $[16,17]$. Oman established its NTP in 1975, which became an integral component of the Dept of Communicable Disease Control at the MOH in 1990. In 1984, the NTP National Committee was set up consisting of concerned stakeholders and by 2014 the committee was integrated into the Communicable Disease National Committee. The NTP is the apex body responsible for formulating national policies and monitoring programme implementation. Every governorate has a TB focal point to monitor the TB programme. Well-established TB programmes are equipped with adequate and trained human resources in central, governorate and treating hospitals.

By 1995, TB treatment was available at all hospitals with appropriate laboratory capacities. Monitoring, follow-up, case finding, contact tracing, screening and evaluation systems were invariably adopted across the country. In addition, the NTP activities have been integrated into the primary, secondary and tertiary healthcare services, and well-financed NTP. TB reporting has been made mandatory for both public and private sectors along with development of $\mathrm{TB}$ registry and surveillance integrated into the National Communicable Disease Surveillance System.

The previous DOTS (directly observed treatment, short course) strategy of WHO, with all its components, was implemented in Oman in 1996. The surveillance activities to monitor and assess TB drug resistance and the treatment of latent tuberculosis infection (LTBI) in high-risk groups were set up in 1998. Furthermore, contacts exposed to bacteriologically confirmed TB cases were screened and assessed, and isoniazid preventive therapy (IPT) in household contacts aged $<5$ years and in people living with HIV (PLHIV) was implemented; the programmatic management of drug-resistant TB (PMDT) was initiated on a large scale in 2006. The provision of TB care, control and prevention services were ensured for foreign-born individuals.

The NTP activities have been integrated into the primary, secondary and tertiary healthcare services provided by the $\mathrm{MOH}$ and in the private sector. At primary healthcare level, TB cases are identified and notified. Presumed TB cases are referred to the closest hospital for the confirmation of TB diagnosis and treatment. 
The national policy on TB prevention, care and control detailed in the national guidelines has been used within the NTP network since 1996.

In 1991, TB reporting was integrated into the National Communicable Disease Surveillance System $[18,19]$. TB case is classified based on WHO case definitions $[18,20]$ and have to be reported to the NTP within $24 \mathrm{~h}$ of the diagnosis with pulmonary TB (PTB) and within a week for those with extrapulmonary TB (EPTB).

All new TB patients are treated with the standard regimens recommended by WHO and PMDT [21-23] that are implemented through the clinical services offered within the NTP network.

\section{Progress towards TB elimination}

On January 4, 1997, the Gulf Health Council (GHC) endorsed the goal of TB Elimination, aiming at reducing the incidence of new smear-positive cases among nationals to fewer than on per 100000 population by 2010. This has been the first TB elimination initiative ever defined at a subregional level in the Eastern Mediterranean Region (EMR) and taken up by the six GHC health ministers [24].

\section{Results}

The overall TB notification rate for all new TB cases declined significantly from 91 to 7.8 per 100000 population during 1981-2016 ( $\mathrm{p}<0.001$ ) (Figure 1). TB notification declined sharply from 91 to 37 cases per 100000 population during 1981-1990 with an average decline rate of $9 \%$ per year. A further decrease from 21 to 14 cases per 100000 population was observed between 1991 and 2000 with a decline rate of 4.5\% per year. During 2001-2010, the decline was from 12 to 10 cases per 100000 population at the average rate of $1.7 \%$ per year. During 2011-2016, the decline was from 11 to 7.8 cases per 100000 population with a $5.7 \%$ decline rate per year. Overall, the TB notification rate has remained below 100 cases per million population since 1991 (Figure 2). The overall downward trend of new TB cases was $92 \%$ during 1981-2016. However, the highest reduction in TB cases was 73\% during 1981-1992.

The annual notification rate of PTB declined by 9\%, 4.5\%, 1.7\% and 5.7\% per year during 1981-1990, 1990-1999, 2000-2009 and 2010-2016, respectively.

During 2010-2016, 2352 patients met the case definition of TB. Of these, 1409 (60\%) cases were Omani nationals and $943(40 \%)$ were foreign-born people. The trend of the notification rate of bacteriological confirmed PTB cases declined among nationals until 2015. The rate increased by $34 \%$ (from 23 to 68 per million population) in 2016, while the decline of the notification rate continued in foreign-born individuals (figure 2).

Among the 943 foreign-born persons, 721 (76\%) were from India, 103 (11\%) from Bangladesh, 66 (7\%) from Indonesia, 25 (3\%) from Pakistan and 28 other nationalities. Moreover, 305 (32\%) of these foreign-born individuals were housemaid workers.

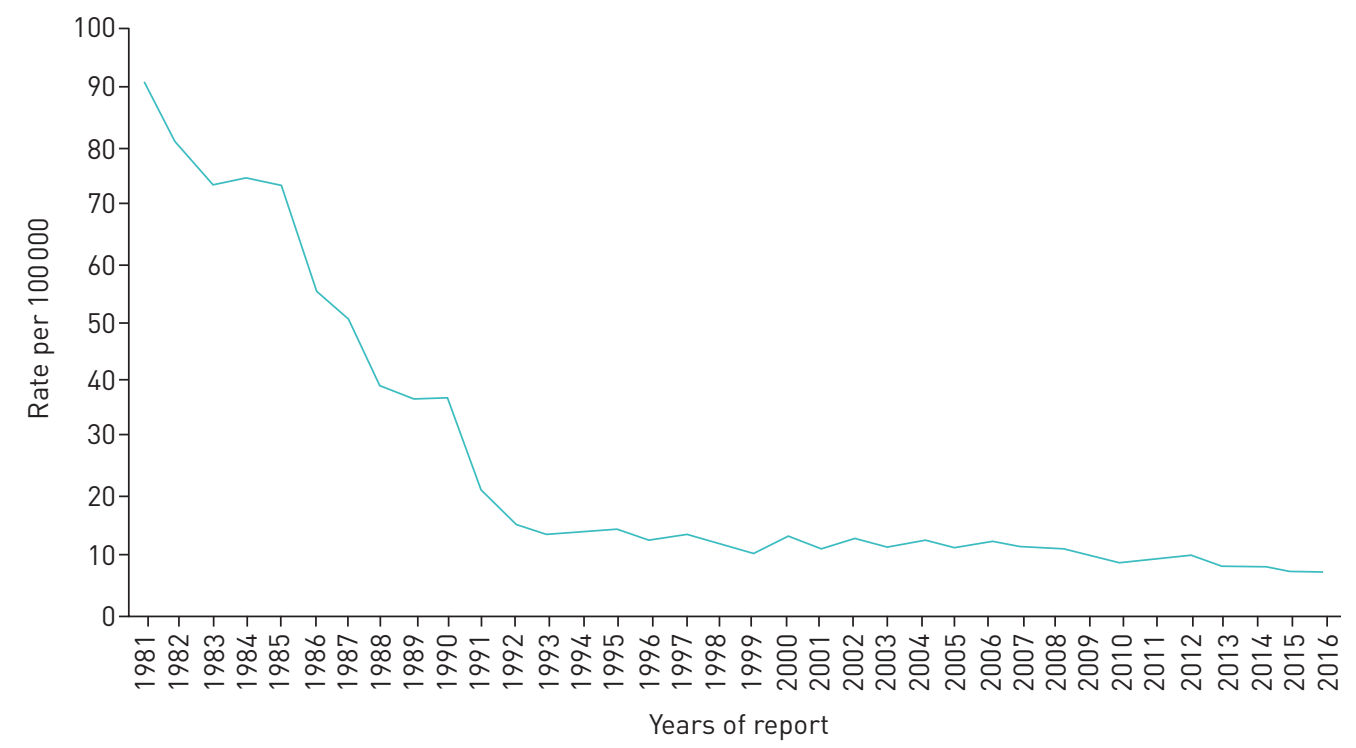

FIGURE 1 Tuberculosis (all) notification rates, Oman, 1981-2016. 


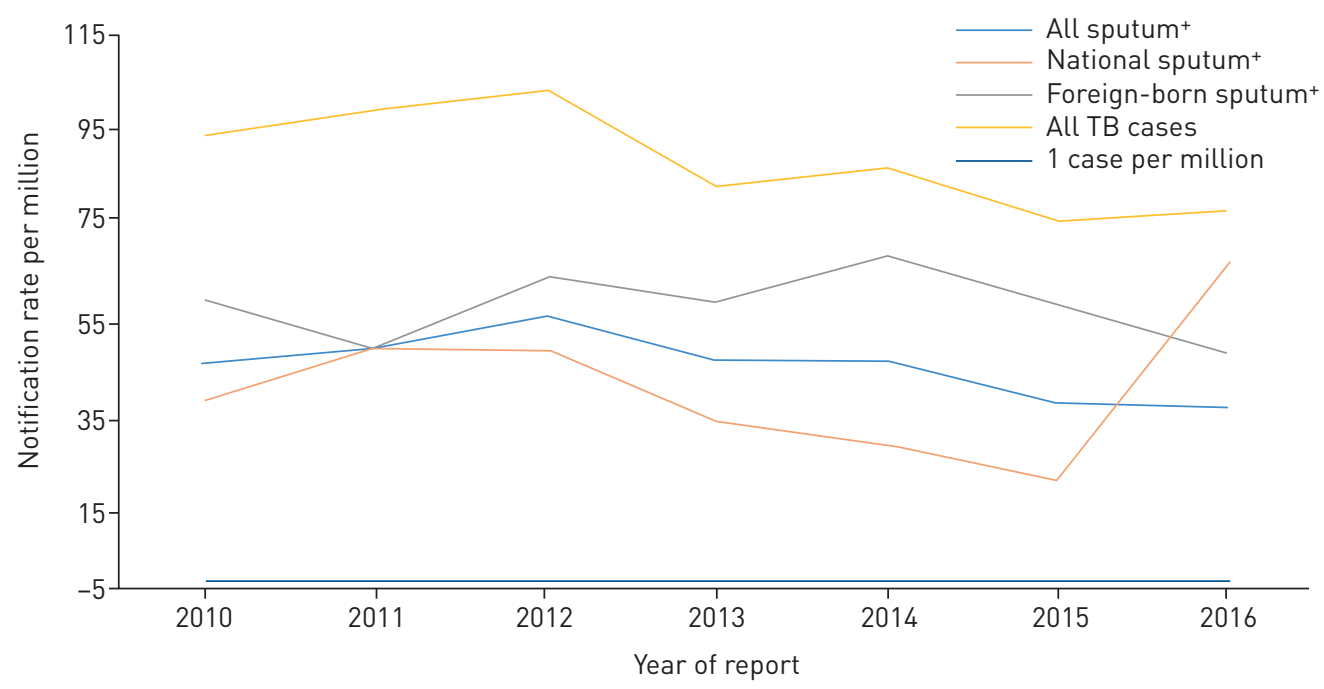

FIGURE 2 Trends in tuberculosis (TB) notification rate, Oman, 2010-2016.

In the 2352 notified TB cases (all types), the average age specific rates per 100000 were 15, 42, 103, 49 and 99 for the age groups 15-19, 20-24, 25-34, 35-44 and >45 years, respectively, and 1895 (80\%) were males. The distribution of TB forms showed that: 1) 1244 (53\%) were PTB patients, of whom 1003 (87\%) were bacteriologically confirmed PTB cases and 283 (12\%) clinically diagnosed PTB cases; and 2) 825 (35\%) were EPTB patients. In 2016, 34\% of 345 TB cases were diagnosed using Xpert MTB/RIF (Cepheid, Sunnyvale, CA, USA).

198 (8\%) notified TB cases, were <14 years of age; among them, 87\% (172 out of 198) were Omani nationals. In this age group, the notified rate ranged between 0.2 and 0.7 per 100000.11 (5\%) children had bacteriologically confirmed PTB, 60 (30\%) had clinically diagnosed TB and 129 (65\%) had EPTB.

During the same period, most of the TB cases (all forms) were notified in the Muscat governorate (average rate 105 per 100000 ), North Batinah (average rate 63 per 100000) and Dhofar governorate (average rate 54 per 100000$)$ as shown in figure $3.12-23 \%$ of TB notifications (18\% on average) were reported by the private health sector. From 2011 to 2016, the diagnosis of PTB within 30 days since the onslaught of symptoms increased from $34 \%$ to $41 \%$ and from $22 \%$ to $49 \%$ among nationals and foreign-born individuals, respectively.

During the period 2010-2016, the TB treatment success [20] was above 87\% (75-100\%) [25, 26]. Fewer than $4 \%$ of patients were lost to follow-up and $3 \%$ not evaluated.

From 2010 to 2016, among 1244 new bacteriologically confirmed PTB cases, 33 (2.7\%) had multidrugresistant (MDR)-TB and only 19 (1.5\%) were tested for HIV. During this period, the annual average rate of notified co-infected TB/HIV cases was 2.4\% (range 1-4\%). During 2014-2016, HIV co-infection showed an increasing trend from $1 \%$ to $3 \%$ among all TB cases.

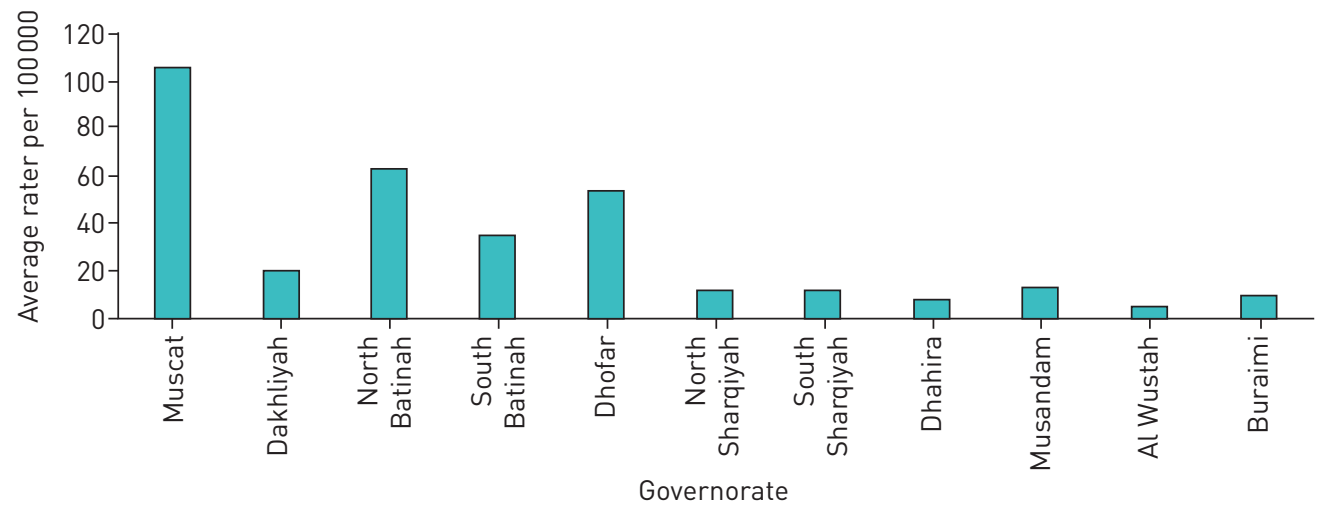

FIGURE 3 Tuberculosis rates by governorate (province), Oman, 2010-2016. 
In 2011, 1327 contacts were identified and 852 (64\%) screened; 124 (15\%) had a positive result either with the tuberculin skin test (TST) or an interferon- $\gamma$ release assay (IGRA). In 2016, of 1473 identified contacts, $1028(70 \%)$ were screened and $142(14 \%)$ had LTBI. In addition, 455 were identified as foreign-born contacts, 410 (90\%) were screened and $80(20 \%)$ had LTBI. TB risk factors among nationals and foreign-born people were diabetes ( $9 \%$ to $13 \%$ ), which exhibited an increasing drift, unlike other risk factors, such as smoking (20\% to $9 \%$ ), family history of TB (15\% to $9 \%$ ) and alcohol abuse (5\% to $3 \%$ ), which showed declining trends.

During 1990-2016, the TB mortality rate dropped by $39 \%$, from 1.8 to 0.71 deaths per 100000 population. TB was the leading cause of death in $<10 \%$ cases, with $90 \%$ deaths recorded among the elderly with other commodities. During 2010-2016, the annual death rate of TB/HIV co-infected cases increased from 0.3 to 0.7 per 100000 population [25-27].

\section{Discussion}

Oman is a low-incidence country [3] where TB notification (all forms) rates have steadily decreased at $<100$ cases per million since 1991. Furthermore, the TB mortality rate dropped by 39\% from 1990 to 2016. Yet, with the current decline in mortality of $2.4 \%$ per year, Oman will not reach the WHO elimination target of the decline in TB mortality $<90 \%$ by 2035 in view of the data obtained in 2015 . The average annual rate of mortality decline required to achieve elimination by 2035 is $11.5 \%$ [3].

Based on recent projections, after 2010, there is a noticeable decline in TB incidence from 94 to 79 per million population (cumulative reduction of $20 \%$ ) and an annual average reduction of $5.7 \%$, which is one of the highest ever observed. However, the rate of decrease per year during the same period is insufficient to achieve the pre-elimination threshold by 2035 ( $<10$ cases per million population) [3]. Rather, with this rate, the pre-elimination target in Oman could only be reached in 2050, requiring an average yearly decline rate of around $12 \%$ [3]. This decline was mainly attributed to well-established TB programme with adequate and trained human resources at centres and hospitals with appropriate laboratory capacities, monitoring, follow-up, case finding, contact tracing, screening and evaluation systems, which were invariably adopted. In addition to a well-financed TB national programme, the NTP activities have been integrated into the primary, secondary and tertiary healthcare services. TB reporting and registration were mandatorily reported and integrated into the National Communicable Disease Surveillance System, and TB diagnosis and treatment were practically available across the country. The provision of TB care, control and prevention services were insured free of charge for all national and foreign-born members of the population. Furthermore, fewer TB cases were reported. Less drug-resistant TB and all cases were managed and treated mainly in one hospital. The TB notification rate increased by $34 \%$ in 2016, attributed to increased involvement of the private sector in reporting $\mathrm{TB}$ cases and enhancing active search for $\mathrm{TB}$ cases, particularly among contacts.

Oman has implemented some of the substantive components of the eight priority actions of the WHO's framework for TB elimination [3-5] and figure 4 summarises the maximum implementation of eight TB priority action areas in Oman by the end of 2016.

Firstly, political commitment has been demonstrated through a strong governance and stewardship of the NTP within the MOH. To this end, a single administrative structure has been established to lead the TB elimination strategy with the NTP central unit and the governorate units. Integration of TB national strategic plans into the 5-year national health plan has been enabled and access to high-quality TB services has been maintained with provision of free TB care services. In addition, a national network of laboratory services has been made available. Quality assurance scheme has been implemented in all laboratories for TB diagnosis. The Central Public Health Laboratory (CPHL) is linked to the supranational TB reference laboratory of Prince Léopold Institute of Tropical Medicine (Antwerp, Belgium) and Institute Superiore DiSanita (Rome, Italy). IGRAs, molecular techniques such as a line probe assay, Xpert MTB/RIF testing and second-line spoligotyping using mycobacterial interspersed repetitive units-variable number tandem repeat analysis are available in the CPHL. Xpert MTB/RIF testing is presently performed in five public tertiary and secondary care facilities and in the private sector.

A national policy of 2006 restricted the use of TB medicines and tests for public sector and health service settings authorised by the $\mathrm{MOH}$. In addition, $\mathrm{TB}$ national policy and guidelines for infection prevention and control have been evolved based on the national and GCC guidelines [28, 29]. These policies have been applied across the country to reduce transmission of infections in healthcare settings.

Secondly, for the most vulnerable populations, systematic TB screening has been implemented among PLHIV and contacts exposed to TB index cases. Those in whom active TB is ruled out, receive IPT. Furthermore, preventive antiretroviral therapy is offered to all PLHIV with TB regardless of their CD4 count [30]. 


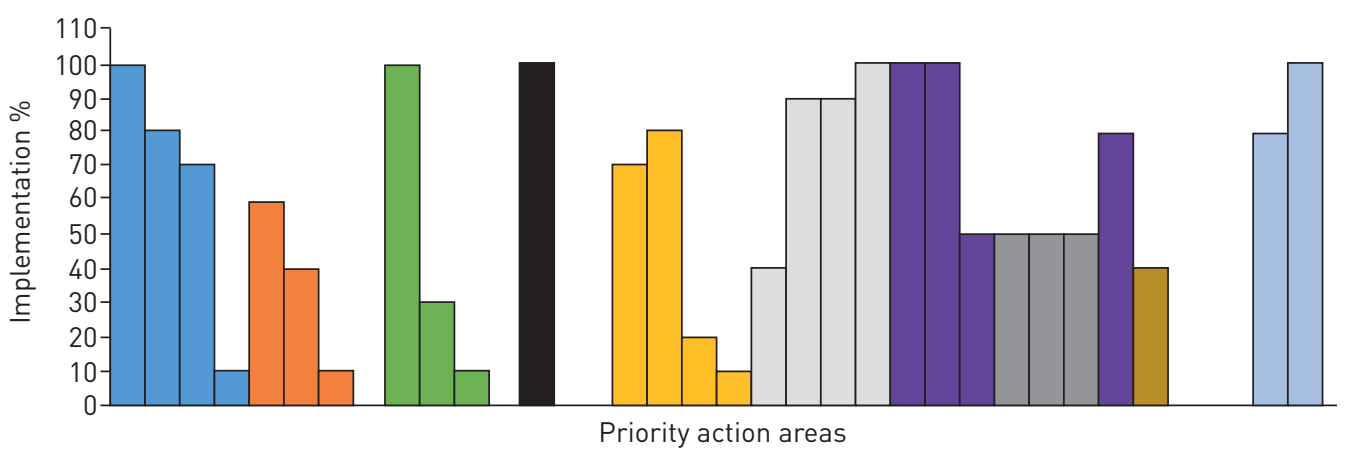

Ensure political commitment, funding and stewardship for planning and essential services of high quality

Address the most vulnerable and hard-to-reach groups

$\square$ Address special needs of migrants and cross-border issues

Undertake screening for active TB and LTBI in TB contacts and selected high-risk groups, and provide appropriate treatment

$\square$ Optimise the prevention and care of drug-resistant TB

$\square$ Ensure continued surveillance programme monitoring and evaluation and case based-data management

Invest in research and new tools

Support global TB prevention, care and control

FIGURE 4 Summary of implementation of eight priority action areas in low-incidence countries, Oman. TB: tuberculosis; LTBI: latent TB infection.

Thirdly, systematic screening of active TB among foreign-born individuals is undertaken at both pre- and post-entry into Oman. The Oman $\mathrm{MOH}$ has designated healthcare services for foreign-born individuals, upon arrival and within a week after arrival. TB screening should be executed as part of overall universal health screening and wellbeing. Systematic screening for TB includes consideration of TB history, physical examination and chest radiography; however, testing (IGRA or TST) has not been adopted. If suspected of having TB, the patient is taken to the nearest hospital for testing with either IGRA or TST, with further management and assessment based on WHO guidelines [31]. TB contact investigation involves a systematic evaluation of the contacts of known TB patients to identify active disease or LTBI. Accordingly, TB preventive treatment has to be implemented. TB diagnosis and treatment, including drug-resistant TB management and patient support, are nominally free of charge regardless of their administrative position to live in Oman. Appropriate social protection strategies for foreign-born TB patients are likewise sought. Foremost of all, the proportion of the foreign-born population originating from high-incidence countries in the early years until 2000 was approximately $30-50 \%$ of foreign-born workers. The notified TB cases received the TB care and control free of charge until they were either converted to negative or felt sound. However, some do leave the country as their personal choice. The possible reasons for foreign-born patients leaving the country shortly after diagnosis of TB were very short-term contracts (6-8 months), discretionary employment practises of the employers and the preference of patients to go home to complete their TB treatment. Pre- and post-TB screening was launched in 1990.

No financial burden is imposed on foreign-born persons regardless of their administrative status to live in Oman.

Fourth, to comply with recommendations on LTBI management, systemic screening is implemented using TST or IGRA among case contacts of people with bacteriologically confirmed TB, including household contacts and adults, adolescents and children (HIV-negative children aged <5 years), the immunocompromised, PLHIV and suspected TB cases among foreign-born individuals upon arrival. Healthcare workers (HCWs) are not part of the cover. Those with active or positive results are given IPT daily for 6 months with a 1-year follow-up. The management of LTBI in contacts $<5$ years used IGRA/ TST for screening. In 2007, LTBI management was expanded to all close contacts of PTB cases and to known immunocompromised patients with a negative TST who converted to positive within 2 years. In 2017, the new regimen combining rifampicin and isoniazid was adopted.

Fifth, systematic HIV testing has been implemented since 1996. MDR-TB surveillance was initiated in 2007 and data on drug susceptibility testing for isoniazid and rifampicin have been collected systematically. During 2007-2016, the prevalence of MDR-TB was 1.2\% among newly diagnosed cases and $2.7 \%$ in TB/HIV co-infected patients. The prevalence of MDR-TB among new cases is low, pointing out that TB medicines are appropriately used in line with the NTP policy and not prescribed in an anarchic 
manner. To avoid misuse, TB drugs are strictly regulated and are available in $\mathrm{MOH}$ institutions only, prescribed by specialised physicians.

Sixth, TB surveillance has used a sound electronic case-based TB register to monitor TB frequency and evaluate its prevention, care and control. The NTP central unit prepares an annual report that compiles monthly summaries from hospitals and clinics belonging to public and private health sectors. Community-driven TB awareness campaigns have taken place. The approach adopted is tailored to the culture and linguistic characteristics of both native and foreign-born communities.

Seventh, Oman needs to identify hypotheses for operational research based on in-depth data analysis generated by the monitoring and evaluation system to improve programme performance.

Finally, it is worth highlighting that the Oman government has backed the international strategy and targets set by WHO, and has been actively collaborating internationally with other members of the GHC and outside, as relevant.

\section{Challenges and the way forward}

The foremost action for the NTP needs to be to review progress and challenges critically on a regular basis, with a focus on key issues that could prevent to achieve the 2035 elimination targets. Some of the key actions include: 1) an urgent need to obtain a suitable national TB elimination follow-up task force and implementation of efficient systematic monitoring; 2) appropriate LTBI management, and strengthening of TB prevention, care and control services as well as systematic testing for and treatment of LTBI to be considered for health workers and foreign-born from countries with a high TB burden supported by appropriate LTBI management, and toning up of TB prevention, maintenance and control services; 3) use of modern tools and new regimens and drugs needs to be swiftly introduced, with special attention given to private institutions; 4) a functional monitoring scheme, with specific 5-year national and governorate operational plans and milestones, need to be developed; 5) progress reports and lessons learned need to be disseminated among policy makers, HCWs and other stakeholders; 6) need for training and increase in awareness of HCWs on an active detection of TB cases, especially among high-risk groups; and 7) an efficient supervision and monitoring system needs to be established at governorate level.

Oman has a significant population of foreign-born persons (approximately 45\% of the overall population) [17] and most of them are from high TB incidence countries [32]. Out of the total notified TB cases, $40 \%$ are identified among foreign-born individuals. Thus, the NTP must give priority to the provision of TB prevention, care and control of foreign-born individuals in order to eliminate TB in Oman; pre-migration screening should be linked with the countries of origin.

Oman has the highest prevalence of diabetes in the world [33-35], which triples the risk of developing TB and may result in adverse outcomes of TB treatment $[36,37]$. Therefore, there is a need to establish a framework for TB care and control in diabetes patients as well as for collaborative activities between the NTP and the national diabetes programme.

TB/HIV co-infection is low (1-4\%) in Oman. A recent study revealed that $3.5 \%$ of TB/HIV co-infected patients received ART in 2016 [1], far below the WHO target of universal ART coverage [38]. Increasing the coverage with ART will substantially reduce the incidence of TB as ART reduces the risk of developing TB by $60 \%$ among PLHIV [39].

Systematic screening for LTBI has shown modest progress from $64 \%$ to $70 \%$ coverage. This implies that $30 \%$ of people are not screened and therefore are at a high risk of developing active TB. Henceforth, there is a need to improve the effectiveness of screening programmes and LTBI management among high-risk groups [40].

$18 \%$ of notified TB cases were reported by the private health sector where majority of the foreign-born persons seek care. Other countries in the EMR showed low reporting from the private sector [41]. NTP activities can be significantly improved through better implementation of appropriate public/private mix approach.

Approximately $40 \%$ of the bacteriologically confirmed PTB cases were diagnosed within 30 days of the onset of symptoms in both national and foreign-born patients, which is in accordance with the $\mathrm{MOH} \mathrm{TB}$ policy. The possible reasons for the late diagnosis include delay in the identification of presumed TB patients by HCWs, mainly at the primary healthcare level. Timely identification of underlying factors needs to be addressed and closely followed up, especially the monthly TB screening targets assigned for primary health care settings by the governorates' TB teams.

To reach the elimination targets, a national plan was declared describing the priorities for operational research based on in-depth data analysis generated by the existing NTP information system [41]. In 
addition, operational research should be pursued to address clear priorities: 1) identification of social, demographic or behavioural determinants associated with TB patients irrespective of their administrative status, and test approaches to address the role of these determinants in TB occurrence, care and control outcomes; 2) implementation of relevant modern tools like Xpert MTB/RIF and use of new drugs and regimens; and 3) development of an appropriate strategy to involve the best care providers practising in the private medical sector.

\section{Conclusions}

Although the NTP of Oman had enforced concrete steps to implement key TB elimination measures as recommended, the current $\mathrm{TB}$ indicators (notably, notifications and deaths) will probably maintain an unfavourable direction if critical interventions are not urgently adopted. These should be adopted in addition to all actions described in the programme that calls for an urgent development of a suitable national TB elimination follow-up task force and implementation of efficient system monitoring. The time has come to act in a more dynamic and organised way to achieve the objective of freeing the Oman population from the century-old TB threat.

Acknowledgement: We are highly in debt to Ali Bin Moosa, the late Ali Jaffer Mohammed, the late Ahmed Al Ghassani, Mohammed Al Hosani, H. Colaso, Ferdosi Mehta, Ali BaOmer, Ali Al Lawati, Hassan Al Tohami, Mohammed Redha (all current or former employees of the $\mathrm{MOH}$, Muscat, Oman), governorate TB focal points and staff at $\mathrm{MOH}$, Salah Aldeen Othmani (formerly WHO, Geneva, Switzerland), Mohammed Faraj (MOH), Adamu Selu (WHO), Magda Al Wahibi $(\mathrm{MOH})$, governorate epidemiologists (MOH), Samiha Baghdadi (WHO Eastern Mediterranean Office, Cairo, Egypt), Mamon El-Sheikh (formerly MOH) and Mario Raviglione (Formerly WHO) for their guidance and support.

Conflict of interest: S.T. Al Awaidy has nothing to disclose.

\section{References}

1 WHO. Global tuberculosis report 2016. http://apps.who.int/medicinedocs/en/d/Js23098en/ Date last updated: June 2, 2016. Date last accessed: June 2, 2016.

2 WHO. TB facts. www.who.int/mediacentre/factsheets/fs104/en/ Date last updated: February 16, 2018. Date last accessed: February 16, 2018.

3 Lönnroth K, Migliori GB, Abubakar I, et al. Towards TB elimination, an action framework for low-incidence countries. Eur Respir J 2015; 45: 928-952.

4 Broekmans JF, Migliori GB, Rieder HL, et al. European framework for tuberculosis control and elimination in countries with a low incidence. Eur Respir J 2002; 19: 765-775.

5 Veen J, Migliori GB, Raviglione M, et al. Harmonisation of TB control in the WHO European region: the history of the Wolfheze Workshops. Eur Respir J 2011; 37: 950-959.

6 Lönnroth K, Migliori GB, Abubakar I, et al. Towards tuberculosis elimination: an action framework for low-incidence countries. Eur Respir J 2015; 45: 928-952.

7 D'Ambrosio L, Dara M, Tadolini M, et al. TB elimination: theory and practice in Europe. Eur Respir J 2014; 43: $1410-1420$.

8 Rendon A, Fuentes Z, Torres-Duque CA, et al. Roadmap for tuberculosis elimination in Latin American and Caribbean countries: a strategic alliance. Eur Respir J 2016; 48: 1282-1287.

9 European Centre for Disease Prevention and Control. Framework action plan to fight tuberculosis in the European Union. https://ecdc.europa.eu/sites/portal/files/media/en/publications/Publications/0803_SPR_TB_Action_plan.pdf Date last updated: December 11, 2008. Date last accessed: December 11, 2008.

10 Al-Maniri $\mathrm{A}, \mathrm{Al}$-Rawas $\mathrm{O}, \mathrm{Al}-\mathrm{Tuhami} \mathrm{H}$, et al. Towards the elimination of tuberculosis in a developing country: 25 years of tuberculosis control in Oman. Int J Tuberc Lung Dis 2007; 11: 175-180.

11 Al-Maniri AA, Fochsen G, Al-Rawas O, et al. Immigrants and health system challenges to TB control in Oman. BMC Health Serv Res 2010; 10: 210.

12 Al-Maniri AA, Al-Rawas OA, Al-Ajmi F, et al. Tuberculosis suspicion and knowledge among general public and private practitioners: questionnaire based study in Oman. BMC Public Health 2008; 8: 177.

13 Khamis F, Al-Lawati A, Al-Zakwani I, et al. Latent tuberculosis in health care workers exposed to active tuberculosis in a tertiary care hospital in Oman. Oman Med J 2016; 31: 298-303.

14 Al Yaquobi F, Al-Abri S, Al-Abri B, et al. Tuberculosis elimination: a dream or a reality? The case of Oman. Eur Respir J 2018; 51: 1702027.

15 Al Awaidy ST, Khamis F. Tuberculosis in Gulf Health Council Member States: opportunities and challenges towards TB elimination. Oman Med J 2018; 33: 181-183.

16 Ministry of Health, Oman. Annual Health Report. www.moh.gov.om Date last updated: August 16, 2016. Date last accessed: August 28, 2016

17 National Center for Statistics \& Information. www.ncsi.gov.om/NCSI_website/N_default.aspx Date last accessed: February 2018

$18 \mathrm{MOH}$, Oman. National Manual of TB Control Programme. 4th Edn. Oman, MOH, 2007.

19 Ministries of Health. Communicable Disease Surveillance \& Control Expanded programme on immunization, Sultanate of Oman. www.cdscoman.org/immunization.html Date last updated: September 3, 2014. Date last accessed: September 3, 2014.

20 WHO. WHO case definition: Definitions and reporting framework for tuberculosis - 2013 revision. http://apps. who.int/iris/bitstream/10665/79199/1/9789241505345_eng.pdf?ua=1 Date last updated: December 20, 2014. Date last accessed: December 20, 2014. 
21 Tuberculosis Coalition for Technical Assistance (TBCTA), WHO. International Standard for Tuberculosis Care www.who.int/tb/publications/2006/istc_report.pdf?ua=1 Date last updated: April 7, 2004. Date last accessed: April 7, 2004.

22 WHO. Guidelines for treatment of drug-susceptible tuberculosis and patient care. www.who.int/tb/publications/ 2017/dstb_guidance_2017/en/ Date last updated: June 20, 2017. Date last accessed: June 20, 2017.

23 WHO. Global Tuberculosis report. 20th Edn. 20th edition. France, WHO, 2015, pp. 1-155.

24 GCC Ministerial Amendment adopted TB Elimination Goal in January 1997. Ministerial meeting No. 42, Ministerial qarar No. 16/42. Abu Dhabi, UAE. January 4, 1997.

25 WHO. Global Health Observatory visualizations, Indicator Metadata Registry. http://apps.who.int/gho/data/node wrapper.imr?x-id=1422 Date last updated: January 15, 2017. Date last accessed: January 15, 2017.

26 WHO. Oman statistical summary. http://apps.who.int/gho/data/node.country.country-OMN?lang=en</authors Date last updated: February 15, 2016. Date last accessed: February 15, 2016.

27 TB Oman profile. https://extranet.who.int/sree/Reports?op=Replet\&name=\%2FWHO_HQ Reports\%2FG2\% 2FPROD\%2FEXT\%2FTBCountryProfile\&ISO2=OM\&LAN=EN\&outtype=pdf Date last updated: March 152013. Date last accessed: March 152013.

$28 \mathrm{MOH}$. GCC Infection Prevention and Control Manual. www.moh.gov.sa/CCC/Documents/GCC\%20Infection\% 20control\%20manual\%202013\%20revisedOPT.pdf Date last updated: April 16, 2013. Date last accessed: March 20, 2016.

$29 \mathrm{MOH}$, Oman. $\mathrm{MOH}$ Code of Practice for Infection Prevention and Control. www.moh.gov.om/documents/ 236878/0/MOH+Code+Practice/4e55e63c-a1dc-4a2d-b813-37ec6915dc60 Date last updated: September 2018. Date last accessed: March 15, 2018.

30 Al-Maani ASS. HIV Management in Oman. In: Al-Lawati MR, Bahha T, Shah S, eds. HIV Management in Oman. A Guide for HCW. 3rd Edn. Oman, Ministry of Health, 2015.

31 WHO. Latent TB infection: updated and consolidated guidelines for programmatic management. www.who.int/tb/ areas-of-work/preventive-care/ltbi_faqs/en/

32 WHO. Global tuberculosis report 2017. www.who.int/tb/publications/global_report/en/ Date last updated: September 14, 2017. Date last accessed: September 26, 2017.

33 Al-Lawati JA. Diabetes Mellitus: A Local and Global Public Health Emergency. Oman Med J 2017; 32: 177-179.

34 Asfour MG, Lambourne A, Soliman A, et al. High prevalence of diabetes mellitus and impaired glucose tolerance in the Sultanate of Oman: results of the 1991 national survey. Diabet Med 1995; 12: 1122-1125.

35 WHO. Tuberculosis and diabetes. www.who.int/tb/publications/diabetes_tb.pdf Date last updated: April 14, 2016. Date last accessed: April 14, 2016.

36 Jeon CY, Murray MB. Diabetes mellitus increases the risk of active tuberculosis: a systematic review of 13 observational studies. PLoS Med 2008; 5: e152.

37 Baker MA, Harries $\mathrm{AD}$, Jeon $\mathrm{CY}$, et al. Systematic review: the impact of diabetes on tuberculosis treatment outcomes. BMC Med 2011; 9: 81 .

38 UNAIDS. Prevention gap report. www.unaids.org/en/resources/documents/2016/prevention-gap Date last updated: April 14, 2016. Date last accessed: April 14, 2016.

39 Williams BG, Granich R, De Cock K, et al. Antiretroviral therapy for tuberculosis control in nine African countries. Proc Natl Acad Sci USA 2010; 107: 19485-19489.

40 Getahun H, Matteelli A, Abu Bakar I, et al. Management of latent Mycobacterium tuberculosis infection: WHO guidelines for low tuberculosis burden countries. Eur Respir J 2015; 46: 1563-1576.

41 Aziz MA, Baghdadi S, Hajjeh R. What would it take to eliminate tuberculosis in the Eastern Mediterranean Region? East Mediterr Health J 2017; 23: 393-394. 